\title{
The Evolving Mechanisms of Action of Glatiramer Acetate
}

\author{
Thomas Prod'homme ${ }^{1}$ and Scott S. Zamvil ${ }^{2}$ \\ ${ }^{1}$ Momenta Pharmaceuticals, Cambridge, Massachusetts 02142 \\ ${ }^{2}$ Department of Neurology and Program in Immunology, University of California, San Francisco, \\ San Francisco, California 94158 \\ Correspondence: zamvil@ucsf.neuroimmunol.org
}

\begin{abstract}
Glatiramer acetate (GA) is a synthetic amino acid copolymer that is approved for treatment of relapsing remitting multiple sclerosis (RRMS) and clinically isolated syndrome (CIS). GA reduces multiple sclerosis (MS) disease activity and has shown comparable efficacy with high-dose interferon- $\beta$. The mechanism of action (MOA) of GA has long been an enigma. Originally, it was recognized that GA treatment promoted expansion of GA-reactive T-helper 2 and regulatory T cells, and induced the release of neurotrophic factors. However, GA treatment influences both innate and adaptive immune compartments, and it is now recognized that antigen-presenting cells (APCs) are the initial cellular targets for GA. The antiinflammatory (M2) APCs induced following treatment with GA are responsible for the induction of anti-inflammatory $T$ cells that contribute to its therapeutic benefit. Here, we review studies that have shaped our current understanding of the MOA of GA.
\end{abstract}

M ultiple sclerosis (MS) is a chronic, progressive, and disabling disorder characterized by immune-mediated demyelination, inflammation, and neurodegenerative tissue damage in the central nervous system (CNS). Relapsing remitting MS (RRMS), characterized by flares followed by partial or complete remission, is the most common MS subtype with $~ 85 \%$ MS patients presenting to their physicians with this disease pattern. The first MS flare, which is not always recognized, is referred to as clinically isolated syndrome (CIS). Approximately $60 \%-70 \%$ of patients with RRMS evolve to secondary progressive MS over time. About $10 \%-15 \%$ of patients have an insidious progressive course from onset, without recognized flares, and are classified as having a primary progressive course.
Whereas MS is not curable, to date, 12 disease-modifying therapies (DMTs) are available for RRMS treatment, partially addressing different aspects of the immune pathophysiology. Glatiramer acetate (GA), together with $\beta$ interferons (IFN- $\beta$ s), is considered first-line treatment for RRMS (Marta and Giovannoni 2012), and is administered subcutaneously or intramuscularly. Although considered the safest medications, they have modest efficacy (Bruck et al. 2013). Second-line drugs have been developed, some that show greater efficacy, including natalizumab (Tysabri), fingolimod (Gilenya), alemtuzumab (Lemtrada), ocrelizumab (Ocrevus) and mitoxantrone (Novantrone), but may have greater potential toxicities. Three of the newer medications, gilenya, teriflunomide (Au-

Editors: Howard L. Weiner and Vijay K. Kuchroo

Additional Perspectives on Multiple Sclerosis available at www.perspectivesinmedicine.org

Copyright (C) 2019 Cold Spring Harbor Laboratory Press; all rights reserved; doi: 10.1101/cshperspect.a029249

Cite this article as Cold Spring Harb Perspect Med 2019;9:a029249 
bagio), and dimethylfumarate (Tecfidera) are administered orally.

GA (Copaxone, Teva Pharmaceuticals), formerly known as copolymer-1, is a synthetic amino acid polymer that was approved in 1996 in the United States and in 2001 in Europe for treatment of RRMS and, later, in 2014 for CIS. GA was discovered in an attempt to generate antigens mimicking myelin basic protein (MBP), a major protein component of the myelin sheath that is considered one of the candidate myelin autoantigens in MS. Specifically, it was thought that GA would induce experimental autoimmune encephalomyelitis (EAE), the most commonly used animal model for MS. Although GA was found to be immunogenic, it was not encephalitogenic, and prevented myelin proteininduced EAE in various species (Teitelbaum et al. 1971, 1973, 1974, 1996). Those results led first to open-label MS trials with GA (Abramsky et al. 1977; Bornstein et al. 1982) and later placebo-controlled trials (Bornstein et al. 1987; Johnson et al. 1995). Since its approval for MS treatment, GA has remained popular for treatment of MS, especially considering some of the potentially life-threatening side effects of other competitors (Miller et al. 2008).

Whereas the mechanism of action (MOA) of GA has been investigated extensively in both mice and humans, it is still not fully understood. GA is able to modulate multiple processes involving both the innate and adaptive immune system, including the expansion of anti-inflammatory M2 monocytes, Thelper (Th)2 cells, and regulatory $\mathrm{T}$ (Treg) cells.

\section{CHEMISTRY AND PHARMACOKINETIC PROFILE}

GA is composed of the acetate salts of four amino acids, L-glutamate, L-lysine, L-alanine, and Ltyrosine (GLAT), with an average molar fraction of $0.141,0.427,0.095$, and 0.338 , respectively, resulting in a mixture of many synthetic peptides of an average length of 45-200 amino acids with an average molecular weight ranging from 4000 to $9000 \mathrm{Da}$. Lysine - the basic amino acid common to these copolymers-is essential for therapeutic benefit, as "gat"-iramer acetate, lack- ing lysine, was ineffective in preclinical EAE studies. The enormous number of potentially active epitopes $\left(10^{30}\right)$ in GA prevents the isolation of specific active peptide, and has long created a challenge for its characterization by available methodologies (Varkony et al. 2009). Using deep analytical methodologies capable of characterizing complex proteins and previously developed to sequence heparin copolymers (Venkataraman et al. 1999), which permitted the development of a generic version of Lovenox (Ozug et al. 2012), Momenta Pharmaceuticals (Cambridge, MA) generated a generic version of Copaxone, leading to the approval of Glatopa (Glatiramer Acetate injection, Sandoz, Princeton, NJ) by the Food and Drug Administration (FDA) in 2015.

GA is hydrolyzed at the site of injection, where it can interact both with antigen-presenting cells (APCs) and lymphocytes (Ziemssen et al. 2001). Some material is then presumed to either reach draining lymph nodes or general circulation. Data obtained from animal models using radiolabeled doses of GA showed that the highest levels were achieved in the stomach and thyroid, and the lowest were in the CNS. The hydrophilic nature of GA and its metabolites might therefore prevent it from crossing the blood-brain barrier, suggesting that the therapeutic effect would preferentially occur in periphery (Carter and Keating 2010). In animals, the main route of elimination was shown to be urinary excretion.

\section{MECHANISMS OF ACTION}

\section{Modulation of the Adaptive Responses}

MOAs of GA that promote immunomodulation and neuroprotection have been described (Fig. 1). Those mechanisms are not mutually exclusive, and several may contribute to the efficacy of the drug.

Given the molecular resemblance to fragments of MBP, GA was shown to bind to major histocompatibility complex (MHC) class II molecules that bind MBP (Fridkis-Hareli et al. 1994, 1997; Fridkis-Hareli and Strominger 1998). Therapeutic effects of GA have been attributed, 

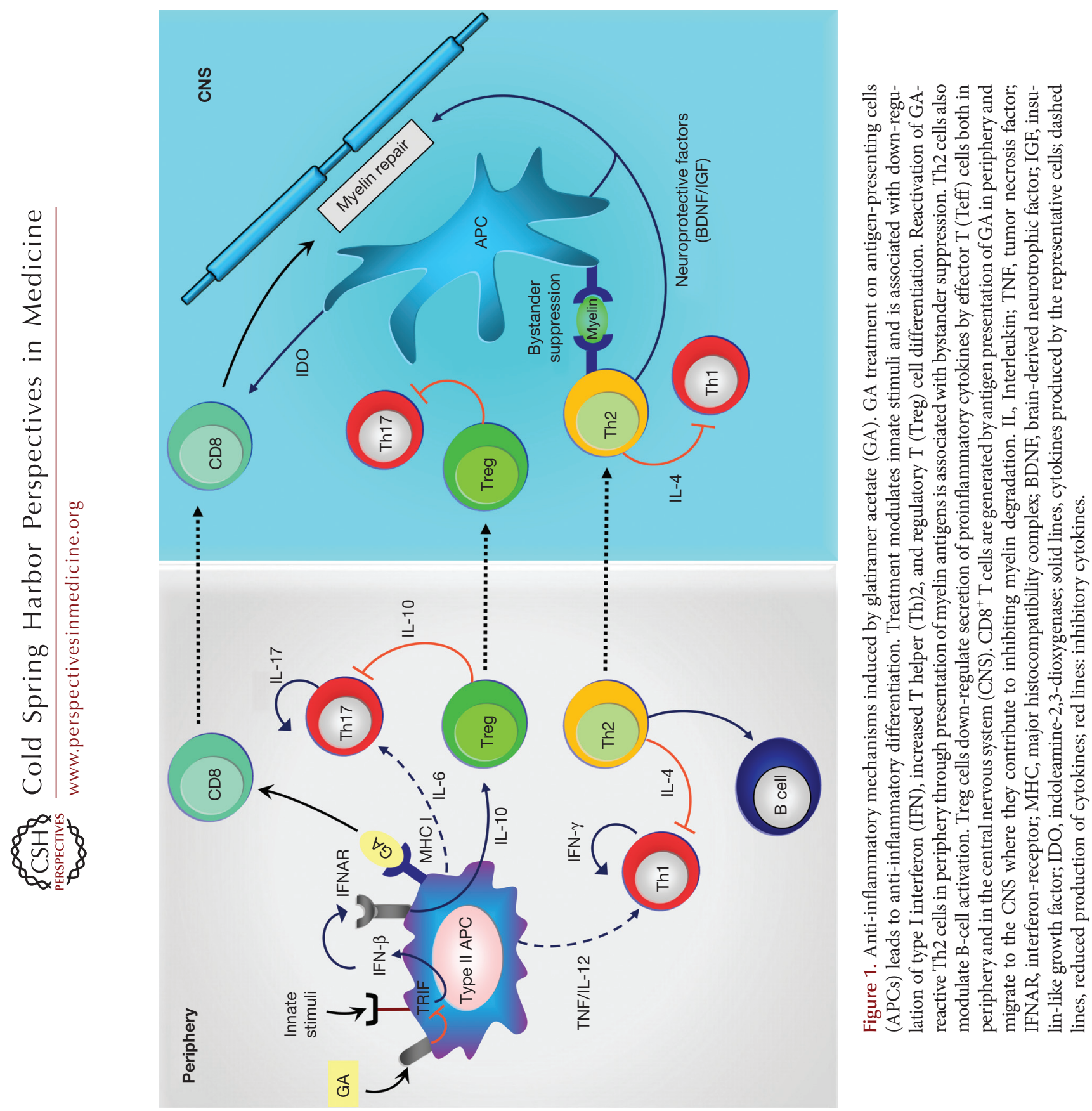
in part, to the ability of antigenic sequences in hydrolyzed GA peptides to act as altered peptide ligands (APLs), antagonizing the activation of MBP-specific T-cell clones (Teitelbaum et al. 1992; Aharoni et al. 1999). However, those results were later challenged by use of a stereoisomer of GA that retained the ability to bind to MHC II, but yet failed to suppress EAE (Aharoni et al. 1997), and by a report showing that the anti-inflammatory properties of GA were preserved in cells devoid of MHC II expression (Weber et al. 2007).

Repeated GA immunization induces a deviation from a proinflammatory Th1 immune response to an "anti-inflammatory" Th2 phenotype, characterized by the secretion of interleukin (IL)-4, -5, -10, -13, -27 and even transforming growth factor (TGF)- $\beta$ (Miller et al. 1998; Aharoni et al. 1999, 2003; Duda et al. 2000; Farina et al. 2001; Mindur et al. 2016). Because GA does not directly penetrate the CNS blood-brain barrier, it was thought that the immunomodulatory functions are mediated by peripheral GA-induced Th2 cells that enter the CNS, which then become reactivated following recognition of myelin antigens. GA-induced Th2 cells not only down-regulate the response MBP-specific T cells, but also other encephalitogenic antigens, including myelin oligodendrocyte protein (MOG) and proteolipid protein (PLP)-reactive T cells in a process called "bystander suppression" (Aharoni et al. 1998; Neuhaus et al. 2000; Sela and Teitelbaum 2001; Dhib-Jalbut 2002; Hestvik et al. 2008).

Recent studies, however, have challenged the requirement for both antigen specificity and Th2 differentiation for GA-mediated immunomodulation. First, it was observed that GA-specific Th2 cells that did not cross-react with MBP, PLP, or MOG-suppressed EAE. Therefore, the capability of regulating EAE by GA-reactive T cells occurred independent of antigen specificity (Weber et al. 2007). Similarly, another study that examined T-cell lines from MS patients treated with GA showed that Th2 differentiation occurred independently of antigen specificity (Allie et al. 2005). Additional evidence against the need for myelin antigen cross-reactivity of GA-reactive $\mathrm{T}$ cells was provided by studies performed in inflammatory diseases unrelated to CNS pathogenicity. Indeed, GA treatment showed some clinical efficacy in various T-celldependent models of inflammation, including experimental autoimmune uveoretinitis (Zhang et al. 2000), inflammatory bowel disease (IBD) (Aharoni et al. 2005b, 2007; Gur et al. 2006; Neesse et al. 2009) and graft rejection (Arnon and Aharoni 2004). Further, experiments with IL-4- and IL-10-deficient mice show that GA still had beneficial effects in suppressing EAE in the absence of these Th2 cytokines (Jee et al. 2006), suggesting that other mechanisms come into play to fully explain the MOA of GA.

Treg cells play an important role in the pathogenesis of autoimmune diseases, and have been shown to be functionally impaired in MS patients (Venken et al. 2008). In addition to inducing Th2 T cells, GA also increases the frequency (Hong et al. 2005; Weber et al. 2007) and function of $\mathrm{CD}^{+} \mathrm{CD} 25^{+}$FoxP3 ${ }^{+}$Tregs (Jee et al. 2007; Haas et al. 2009). GA was also shown to down-regulate Th17 T-cell differentiation (Aharoni et al. 2010), considered as one of the main pathogenic drivers for CNS autoimmune diseases.

Although the function and clinical relevance of $\mathrm{CD}^{+} \mathrm{T}$ cells in GA treatment is not yet fully understood, GA-specific $\mathrm{CD}^{+} \mathrm{T}$ cells show similar suppressive functions as $\mathrm{CD} 4^{+}$Tregs. In EAE, adoptive transfer of GA-induced $\mathrm{CD}^{+} \mathrm{T}$ cells results in amelioration of the disease. Indoleamine-2,3-dioxygenase (IDO), a tryptophan-metabolizing enzyme that is strongly up-regulated in lymphoid tissues by proinflammatory molecules, is required for the generation of these cells (Tyler et al. 2013). This suppressive activity is impaired in naïve MS patients (Karandikar et al. 2002), but restored following GA treatment, which was induced by both proliferative responses and enhanced cytotoxic ability (Karandikar et al. 2002; Biegler et al. 2006; Tennakoon et al. 2006).

\section{Anti-Inflammatory Effects of GA on APCs}

Studies have suggested that the immunomodulatory effects of GA are not limited to the adaptive immune compartment, but rather result in 
a broad, antigen-independent modulation of bone marrow-derived (myeloid) APCs, which are cells within the innate immune system.

GA was found to be able to switch APC activation from a proinflammatory $\mathrm{M} 1$ to an antiinflammatory M2 differentiation (Hussien et al. 2001; Jung et al. 2004; Weber et al. 2004, 2007; Sanna et al. 2006; Molnarfi et al. 2015). GAtreated monocytes and macrophages can produce increased amounts of IL-10, TGF- $\beta$, secreted IL-1 receptor antagonist (sIL-1Ra), and, conversely, lower levels of IL-12, IL-1 $\beta$, and tumor necrosis factor (TNF)- $\alpha$ (Vieira et al. 2003; Jung et al. 2004; Kim et al. 2004; Weber et al. 2004, 2007; Burger et al. 2009; Carpintero et al. 2010). Type II differentiation was also observed with CNS cell types, in which GA promoted the phagocytic activity of microglia and increased the secretion of IL-10 while decreasing TNF- $\alpha$ (Chabot et al. 2002; Pul et al. 2011), suggesting a general effect on myeloid monocytic cells. The relevance of the in vitro observations was validated in GA-treated MS patients. Reduction of cell activation and cytokine secretion was observed in circulating monocytes (Kim et al. 2004; Weber et al. 2004; Carpintero et al. 2010; Pul et al. 2012) and also in plasmacytoid dendritic cells (DCs) of MS patients (Stasiolek et al. 2006).

A growing body of evidence suggests GAinduced type II (M2) differentiation of myeloid cells may be primarily responsible for the effects observed on T cells, including the promotion of Th2 and Treg differentiation. Expansion of Th2 and Treg cells was also observed in vivo, following adoptive transfer of M2 monocytes, and was associated with a reduction of EAE severity (Weber et al. 2007). However, modulations of the T-cell compartment appear to occur independently of antigen specificity (Kantengwa et al. 2007; Weber et al. 2007). Thus, whereas GA mediates a primary effect on APC independent of T cells, M2 APC-induced Treg T-cell populations appear to be the effector cells of GA-mediated immune modulation.

Although the molecular mechanisms required for GA-mediated M2 differentiation and therapeutic efficacy have remained elusive, GA has been hypothesized to interact with cellsurface receptors, leading to the activation of second messengers and regulatory signaling pathways. It was originally speculated that the interaction of GA with either CD11b or MHC II, both expressed at the surface of myeloid cells, might contribute to GA-mediated modulation (Stapulionis et al. 2008; Toker et al. 2011). However, two studies (Weber et al. 2007; Molnarfi et al. 2015) using CD11b- and MHC II-deficient mice showed that neither CD11b expression nor MHC II expression were required for GA-mediated M2 differentiation. Although the receptor responsible for M2 differentiation has yet to be identified, PI3K (Carpintero et al. 2010; Molnarfi et al. 2015), but not cyclic adenosine monophosphate (cAMP), has been shown to participate in M2 polarization by GA, supporting a central role for PI3K/Akt in regulating inflammatory responses. It was also observed that GA treatment was associated with inhibition of signal transducers and activators of transcription (STAT) 1 in type II monocytes, indicating that GA affected at least one proinflammatory signaling pathway within these cells (Fig. 2) (Weber et al. 2007). Interestingly, GA has been shown to inhibit monocyte reactivity in response to engagement of Toll-like receptors (TLRs) (Weber et al. 2004, 2007), suggesting that modulation of innate signaling could represent a principal MOA of GA. TLR engagement mainly triggers activation of either myeloid differentiation primary response gene 88 (MyD88) or Toll-IL-1 receptor domain-containing adaptor-inducing IFN- $\beta$ (TRIF), which are important in CNS autoimmunity (Guo et al. 2008; Prinz et al. 2008; Prod'homme and Zamvil 2008). Signaling via TRIF leads to activation of IFN regulatory factor 3 (IRF3) transcription factor and subsequent production of IFN- $\beta$. Signaling through TRIF, IRF3, or the type I IFN-receptor (IFNAR) also influences development of Th17 cells and EAE (Guo et al. 2008; Prinz et al. 2008; Fitzgerald et al. 2014). Using various genetically modified mouse strains, as well as human monocytes, Molnarfi and colleagues (Molnarfi et al. 2015) showed that GA inhibited the TRIF-dependent pathway, resulting in a reduction of IFN- $\beta$ production (Fig. 2). This observation is consistent with the earlier demonstration that STAT1 phosphorylation is reduced on acti- 


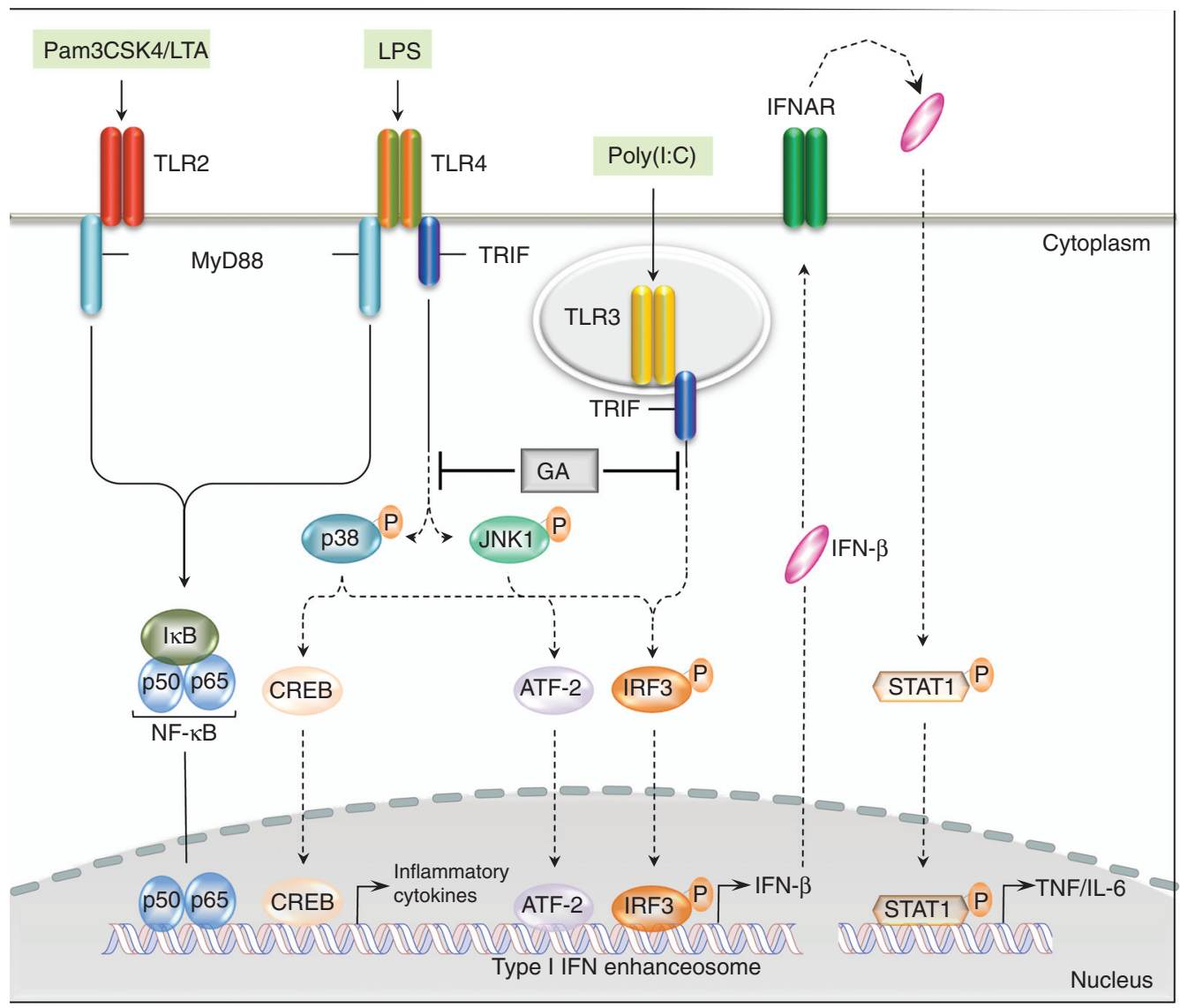

Figure 2. Glatiramer acetate (GA) treatment modulates type I interferon (IFN) production. GA treatment downregulates Toll-IL-1 receptor domain-containing adaptor-inducing IFN- $\beta$ (TRIF) signaling on antigen-presenting cells (APCs), leading to decreased activation of IFN regulatory factor 3 (IRF3) and ATF-2, and subsequent DNA binding of the type I IFN enhanceosome (Molnarfi et al. 2015). Reduction of IFN- $\beta$ production results in decreased signal transducers and activators of transcription (STAT) 1 phosphorylation and activation of proinflammatory cytokines. LPS, Lipid peroxidation; IFNAR, interferon-receptor; TLR, Toll-like receptor; MyD88, myeloid differentiation primary response gene 88 ; TNF, tumor necrosis factor.

vation in type II monocytes (Weber et al. 2007). These findings provide a key anti-inflammatory mechanism connecting innate and adaptive immune modulation in GA therapy.

In addition to inducing M2 myeloid cells, GA can also modulate B cells and promote differentiation of regulatory B cells (Kala et al. 2010). B cells from GA-treated mice show an increased production of IL-10, reduced expression of costimulatory molecules, and diminished proliferation of MOG-specific $\mathrm{T}$ cells. GA treatment also inhibited B-cell release of proinflammatory cytokines, including IL-6,
IL-12, and TNF- $\alpha$ (Begum-Haque et al. 2010). Although these results suggest that B cells may be important to the protective effects of GA in CNS autoimmunity, it is yet to be shown whether this effect is primarily achieved by an altered Bcell APC function, or through the modulation of the cytokine environment or T-cell activation.

The majority of patients treated with GA have been shown to develop GA-reactive antibodies, which, unlike antibodies against IFN- $\beta$, do not seem to interfere with the MOA of GA (Teitelbaum et al. 2003; Karussis et al. 2010; Sellebjerg et al. 2012). Moreover, relapse-free pa- 
tients develop higher immunoglobulin (Ig)G titer (Brenner et al. 2001), and GA-specific antibodies in an animal model of CNS demyelinating disease were shown to promote myelin repair (Ure and Rodriguez 2002), suggesting a possible beneficial effect rather than a neutralizing one. Antibodies belong to the IgG class with a bias toward higher IgG1 titers than IgG2 (Brenner et al. 2001; Basile et al. 2006), followed by increased IgG4 titers over time, probably reflecting a switch toward a Th2 response (Farina et al. 2002).

\section{Neuroprotective Effects}

A growing body of evidence also suggests that GA may exert neuroprotective activities. In EAE, GA treatment has been associated with a reduction of axonal damage and degeneration, as well as with an increase of myelin repair (GilgunSherki et al. 2003; Aharoni et al. 2008). Neuroprotective effects of GA were also supported by the increased axonal integrity observed in GAtreated patients, either by magnetic resonance imaging (MRI) with a reduction of severe lesions ("black holes") (Filippi et al. 2001) or brain proton magnetic resonance spectroscopy $(1 \mathrm{H}$ MRS) (Khan et al. 2008).

GA has been shown to be able to increase secretion of various neurotrophic factors, including brain-derived neurotrophic factor (BDNF), neurotrophin-3 (NT)-3, NT-4, insulin-like growth factor (IGF)-1, and IGF-2. Neuroprotective effects of GA have been observed in various conditions, from neuroinflammation (EAE and MS) to neurodegenerative diseases, including Parkinson's disease, Alzheimer's disease (AD), and amyotrophic lateral sclerosis (ALS) (Kipnis et al. 2000; Angelov et al. 2003; Benner et al. 2004; Aharoni et al. 2005c, 2007; Frenkel et al. 2005; Butovsky et al. 2006; Laurie et al. 2007; Ben-Zeev et al. 2011).

Increased expression of IGF and NT was observed in astrocytes and neurons in situ, suggesting a neuroprotective effect of GA in lesions (Aharoni et al. 2005a). Remyelination induced by GA has also been associated with increased proliferation, differentiation, and survival of oligodendrocyte precursor cells (OPCs), which was specifically related to elevated levels of both IGF-1 and BDNF (Skihar et al. 2009).

BDNF is expressed on most immune cells, as well as activated astrocytes, and is involved in the survival and differentiation of neurons and glial cells. BDNF was found to be up-regulated in both Th1 and Th2 GA-specific T-cell lines in vitro (Kipnis et al. 2000; Ziemssen et al. 2002; Chen et al. 2003) and has also been shown to modulate EAE severity (Linker et al. 2010). BDNF was up-regulated in the CNS of GA-treated mice, whether adoptively transferred with GA-specific T cells (Aharoni et al. 2003) or directly injected with GA (Aharoni et al. 2005a). In addition, induction of BDNF by GA is also observed in MS patients (Azoulay et al. 2005; Blanco et al. 2006; Sarchielli et al. 2007).

A phase III trial, enrolling 943 patients randomized with either GA or placebo for 36 months, addressed the influence of GA in primary progressive MS (PPMS) and did not show a clear clinical benefit in this population (Wolinsky et al. 2007). Furthermore, because it is a matter of debate whether PPMS is prominently caused by neurodegeneration (Steinman and Zamvil 2016), one can question whether the observed reduction in myelin injury occurs primarily from the release of BDNF or from the blockade of inflammatory pathways and restoration of the integrity of the blood-brain barrier, especially because both effects might occur simultaneously (Lalive et al. 2011).

\section{CLINICAL ASPECTS}

FDA approval of GA for RRMS was based upon results of the placebo-controlled trials, one of which was a multicenter phase III study that enrolled 251 patients. The study's primary end point was the mean relapse rate (RR), which was reduced by $29 \%$ in the GA-treated group compared with the placebo group (Johnson et al. 1995). The study was extended by up to 11 months in a double-blind fashion and showed a $32 \%$ reduction in $\mathrm{RR}$ in the treatment group and, conversely, an increase in the proportion of patients that were relapse free (Johnson et al. 1998). At the end of the extension study, $83 \%$ of the originally randomized patients were reen- 
rolled in an open-label study to determine the effect of long-term treatment. At the 8-year time point, GA-treated patients showed clinical improvements compared to the placebo group. The annualized relapse rate (ARR) was 0.43 in the GA group versus 0.52 in the placebo group, and the proportion of patients with stable or improved expanded disability status scale (EDSS) was $65.3 \%$ in GA-treated patients versus $50.4 \%$ in the placebo group (Johnson et al. 2003, 2005). After 10 years, patients receiving GA experienced an increase of mean EDSS score of $0.5( \pm 1.65)$, an $80 \%$ decline in RR compared with placebo, and $91 \%$ of patients remained ambulatory without assistance (Ford et al. 2006). No toxicity was reported after up to 22 years of treatment, confirming the safety profile of GA.

A limitation of the pivotal trial was that it did not include sufficient monitoring by MRI. The effect of GA on MRI parameters was subsequently addressed in a European/Canadian trial, which consisted of two studies, each lasting 9 months. The first treatment phase, involving 239 RRMS subjects, was randomized, doubleblind, and placebo controlled. Patients were injected daily with either $20 \mathrm{mg}$ GA or placebo, and were followed with monthly brain MRIs (Comi et al. 2001). GA-treated patients showed a significant reduction in total gadolinium (Gd)-enhancing lesions compared with placebo, number and volume of new T2 lesions, brain atrophy progression, as well as clinical efficacy measured by reduction of mean RR. The short duration of the study prevented assessment of treatment effects on disability progression. A substudy of the European/Canadian Imaging Study, showed that, at 8 months, $15.6 \%$ in the GA group and $31.4 \%$ in the placebo group had evolved into permanent black holes, representing permanently damaged tissue (Filippi et al. 2001). Further analysis of the imaging data from this trial confirmed the reduction in accumulation of brain atrophy (Sormani et al. 2004).

In the second, open-label, phase of the European/Canadian study, patients were only administered with GA. The effect of treatment was sustained, with a $54 \%$ reduction in the mean number of Gd-enhancing lesions for those switching from placebo to GA and a further $24.6 \%$ reduction for those remaining on GA (Wolinsky et al. 2002). A long-term follow-up over a period of 5.8 years did not show significant differences for any MRI parameters between originally GA- or placebo-treated subjects, but showed an increased proportion of patients not requiring walking aids in the treated group, suggesting a favorable impact on longterm disease evolution (Rovaris et al. 2007).

GA treatment also reduces risk of conversion from CIS to clinically definite MS (CDMS). Here, GA was studied in the 36month, placebo-controlled, randomized, double-blind, phase III (PreCISe) trial. Four hundred eighty-one patients with a monofocal CIS and two or more $\mathrm{T}_{2}$ brain lesions $(\geq 6 \mathrm{~mm}$ ) were randomly assigned to either daily subcutaneous (SC) GA $20 \mathrm{mg}$ or placebo. The primary end point was the time to conversion to CDMS, whereas secondary end points included measures of MS activity by MRI parameters. GA reduced both the risk of conversion to CDMS and the number of new $\mathrm{T}_{2}$ lesions (Comi et al. 2009).

In summary, these three trials consistently showed the efficacy of GA in the treatment of patients with RRMS or CIS, showing an approximately $30 \%$ reduction in RR and benefits on MRI measures of disease activity.

\section{Comparator Trials}

GA, along with various IFN- $\beta$ s, is considered first-line therapy in the treatment of MS. Three large, multicenter randomized clinical trials have been performed to compare the efficacy and safety of GA and IFN- $\beta$ in RRMS patients (Mikol et al. 2008; Cadavid et al. 2009; O’Connor et al. 2009).

The REGARD study was a randomized, open-label trial comparing SC IFN- $\beta 1$ a (Rebif; EMD Millipore) three times a week to daily SC GA $20 \mathrm{mg}$ in 764 RRMS patients. No differences between the two treatment groups were observed after 96 weeks, either in the time to relapse or the number or volume of active $\mathrm{T}_{2}$ lesions. Whereas the IFN- $\beta 1$ a group presented lower Gd-enhancing lesions compared with 
the GA group, GA-treated patients showed significantly less brain atrophy than the IFN-treated group (Mikol et al. 2008).

The BEYOND study involved 2244 RRMS patients, randomized to either $250 \mu \mathrm{g}$ SC or 500 IFN- $\beta 1$ b (Betaseron) every other day or daily SC GA $20 \mathrm{mg}$ over a minimum of 2 years. Results did not show statistically significant differences between groups in ARR, disability progression, and most MRI parameters (Gd-enhancing lesions, $\mathrm{T}_{1}$ lesions, normalized brain volume) (O’Connor et al. 2009).

Finally, the BECOME study compared radiological efficacy of SC IFN- $\beta 1 \mathrm{~b} 250 \mu \mathrm{g}$ every other day with daily SC GA $20 \mathrm{mg}$, over a period of 2 years in 75 RRMS and CIS patients (Cadavid et al. 2009). Similar to the other studies, results did not show significant differences between groups in the number of combined active lesions per patient per scan at year 1 .

Although the three large head-to-head trials were designed with the intent to show superiority of high-dose IFN, they ended up demonstrating that GA has comparable efficacy to high-dose IFN- $\beta$ s in the treatment of RRMS, both from a clinical and radiological perspective. The only notable difference is that GA displayed a better protection against brain-volume loss, whereas IFN- $\beta$ s showed fewer Gd-enhancing lesions.

Among all the other MS therapeutics, the efficacy of GA was only compared with Tecfidera (BG-12) in the phase III CONFIRM trial (Fox et al. 2012). This multicenter, placebo-controlled trial involved 1417 RRMS patients randomized either to BG-12 $240 \mathrm{mg}$ twice a day, BG-12 $240 \mathrm{mg}$ three times a day, GA $20 \mathrm{mg}$ SC daily, or placebo, and treated for 2 years. Although the study was not powered to address the comparison between BG-12 and GA, both BG-12 doses showed similar or superior results compared with GA across all end points, although neither drug significantly reduced disability progression.

\section{Combination Therapies}

Considerable effort has been devoted to the identification of therapeutics that may provide additive or synergistic benefit when combined for treatment of MS (Stuve et al. 2006; Metz et al. 2009; Zamvil and Steinman 2011). Although mixed results were obtained when GA was tested in combination with type I IFNs in preclinical studies (Brod et al. 2000; Soos et al. 2002), GA and IFN- $\beta 1$ a were tested in the randomized, double-blind, placebo-controlled, multicenter, phase III CombiRx trial. The study, involving 1008 participants, showed that combining the two most commonly prescribed therapies for MS did not provide any added benefit in reducing disease progression, compared with either agent alone. In fact, GA alone or in combination with IFN- $\beta$, showed more efficacy than IFN- $\beta$ in reducing the risk of relapse (Lublin et al. 2013). Interestingly, although the results of the CombiRx trial did not identify clinical benefit from the combination of GA and intramuscular IFN- $\beta 1 \mathrm{a}$, they did not provide clear evidence of antagonism either. It is of interest that one mechanistic study observed GA-induced M2 monocyte polarization through down-regulation of IFN- $\beta$ signaling and production (Molnarfi et al. 2015), raising the possibility that GA could antagonize IFN- $\beta$ in some situations.

\section{High-Dose GA and Different Regimens}

GA was originally approved as $20 \mathrm{mg}$ once-daily $\mathrm{SC}$, but some data have suggested that higher doses were associated with greater efficacy (Teitelbaum et al. 1999). Efficacy, safety, and tolerability of $40 \mathrm{mg}$ and $20 \mathrm{mg}$ daily doses of SC GA were evaluated in a phase II and III clinical trials in RRMS patients (Cohen et al. 2007; Comi et al. 2011). Although results from the earlier phase II trial suggested that higher dose GA would be more effective (Cohen et al. 2007), the phase III trial (FORTE) found there was no gain in efficacy with higher daily GA, indicating a ceiling had been reached. Similar efficacy and safety profiles were observed for $40 \mathrm{mg}$ and 20 mg daily doses. These findings raised the possibility that it might be possible to achieve similar benefit from less frequent administration of the higher dose.

The efficacy and safety of a three-times weekly $40 \mathrm{mg}$ GA dosing was evaluated in the randomized, placebo-controlled, phase III "GALA" 
trial (Khan et al. 2013), which compared that regimen with the approved daily SC $20 \mathrm{mg}$ in treatment of RRMS. Thrice-weekly $40 \mathrm{mg}$ dosing showed comparable results to the pivotal $20 \mathrm{mg}$ trial with a significant $(34 \%)$ reduction in ARR, which led to the approval of this treatment schedule of GA (Copaxone) by the FDA in 2014. A generic three-times weekly $40 \mathrm{GA}$ version, manufactured by Mylan Pharmaceuticals, was later approved in 2017.

\section{SAFETY PROFILE}

GA is considered to have the most favorable adverse effect profile compared with the other MS therapies. In this regard, the safety profile of GA in RRMS has been confirmed by long-term studies for up to 22 years (Ford et al. 2010). The typical flu-like reaction characteristic of IFN- $\beta$ does not occur with GA and, unlike IFNs, natalizumab, and fingolimod, GA does not cause liver function abnormalities or leukopenia, depression, or fatigue (Simone et al. 2006; Kieseier and Stuve 2011). The most common adverse effect, occurring in $80 \%$ of patients, is a local injection site reaction experienced as erythema and pruritus. Up to $10 \%-15 \%$ RRMS patients treated with $20 \mathrm{mg}$ GA daily also experience a self-limited postinjection systemic reaction, characterized by chest tightness, shortness of breath, and palpitations. These reactions are unpredictable and can be mistaken for cardiac ischemia, but are not considered dangerous and only require proper patient education and reassurance from the clinician. The frequency of these immediate postinjection reactions (IPIRs) is lower when using $40 \mathrm{mg}$ three times weekly, in part, because of the lower frequency of administration (Khan et al. 2013).

According to FDA classification of fetal risk as a result of pharmaceuticals, GA is a category B drug in the United States, defined as "no controlled human studies are available but animal studies show either no risk or minimal risk to the fetus" and should be used during pregnancy only if clearly needed. Although there are no wellcontrolled studies in pregnant women, administration of GA to pregnant rats and rabbits did not result in adverse effects on offspring develop- ment. There is no apparent impact of paternal exposure to GA on birth outcome or child health. Overall, GA is considered to be safe, even in early pregnancy, although most clinicians will stop its use during pregnancy.

\section{CONCLUDING REMARKS}

Over the last two decades, significant progress has been made both in elucidating the MOA of GA and establishing the long-term clinical benefit to patients. GA has well-characterized immunomodulatory properties, promoting expansion of anti-inflammatory and regulatory Th2 and Treg cells. Animal studies have shown that GA-reactive Th2 cells migrate to the CNS and accumulate at the site of active lesions. Thus, GA-reactive $\mathrm{T}$ cells provide the effector arm in treatment. However, more recent evidence indicates that APCs are the initial target of GA, and it is the modulation of the APC compartment to anti-inflammatory (M2) phenotype that is responsible for both expansion of regulatory Th2 and Treg cells. Although challenged by the development of various emerging therapies, due to both the excellent long-term safety profile of GA and its comparable clinical benefit to other first-line therapies, it is anticipated that GA will continue to be used in MS therapy in the future.

\section{REFERENCES}

Abramsky O, Teitelbaum D, Arnon R. 1977. Effect of a synthetic polypeptide (COP 1) on patients with multiple sclerosis and with acute disseminated encephalomeylitis. Preliminary report. J Neurol Sci 31: 433-438.

Aharoni R, Schlegel PG, Teitelbaum D, Roikhel-Karpov O, Chen Y, Arnon R, Sela M, Chao NJ. 1997. Studies on the mechanism and specificity of the effect of the synthetic random copolymer GLAT on graft-versus-host disease. Immunol Lett 58: 79-87.

Aharoni R, Teitelbaum D, Sela M, Arnon R. 1998. Bystander suppression of experimental autoimmune encephalomyelitis by $\mathrm{T}$ cell lines and clones of the Th2 type induced by copolymer 1. J Neuroimmunol 91: 135-146.

Aharoni R, Teitelbaum D, Arnon R, Sela M. 1999. Copolymer 1 acts against the immunodominant epitope 82-100 of myelin basic protein by $\mathrm{T}$ cell receptor antagonism in addition to major histocompatibility complex blocking. Proc Natl Acad Sci 96: 634-639.

Aharoni R, Kayhan B, Eilam R, Sela M, Arnon R. 2003. Glatiramer acetate-specific $\mathrm{T}$ cells in the brain express $\mathrm{T}$ 
helper $2 / 3$ cytokines and brain-derived neurotrophic factor in situ. Proc Natl Acad Sci 100: 14157-14162.

Aharoni R, Eilam R, Domev H, Labunskay G, Sela M, Arnon R. 2005a. The immunomodulator glatiramer acetate augments the expression of neurotrophic factors in brains of experimental autoimmune encephalomyelitis mice. Proc Natl Acad Sci 102: 19045-19050.

Aharoni R, Kayhan B, Arnon R. 2005b. Therapeutic effect of the immunomodulator glatiramer acetate on trinitrobenzene sulfonic acid-induced experimental colitis. Inflamm Bowel Dis 11: 106-115.

Aharoni R, Yussim A, Sela M, Arnon R. 2005c. Combined treatment of glatiramer acetate and low doses of immunosuppressive drugs is effective in the prevention of graft rejection. Int Immunopharmacol 5: 23-32.

Aharoni R, Sonego H, Brenner O, Eilam R, Arnon R. 2007. The therapeutic effect of glatiramer acetate in a murine model of inflammatory bowel disease is mediated by antiinflammatory T-cells. Immunol Lett 112: 110-119.

Aharoni R, Herschkovitz A, Eilam R, Blumberg-Hazan M, Sela M, Bruck W, Arnon R. 2008. Demyelination arrest and remyelination induced by glatiramer acetate treatment of experimental autoimmune encephalomyelitis. Proc Natl Acad Sci 105: 11358-11363.

Aharoni R, Eilam R, Stock A, Vainshtein A, Shezen E, Gal H, Friedman N, Arnon R. 2010. Glatiramer acetate reduces Th-17 inflammation and induces regulatory T-cells in the CNS of mice with relapsing-remitting or chronic EAE. J Neuroimmunol 225: 100-111.

Allie R, Hu L, Mullen KM, Dhib-Jalbut S, Calabresi PA. 2005. Bystander modulation of chemokine receptor expression on peripheral blood $\mathrm{T}$ lymphocytes mediated by glatiramer therapy. Arch Neurol 62: 889-894.

Angelov DN, Waibel S, Guntinas-Lichius O, Lenzen M, Neiss WF, Tomov TL, Yoles E, Kipnis J, Schori H, Reuter A, et al. 2003. Therapeutic vaccine for acute and chronic motor neuron diseases: Implications for amyotrophic lateral sclerosis. Proc Natl Acad Sci 100: 4790-4795.

Arnon R, Aharoni R. 2004. Mechanism of action of glatiramer acetate in multiple sclerosis and its potential for the development of new applications. Proc Natl Acad Sci 101: 14593-14598.

Azoulay D, Vachapova V, Shihman B, Miler A, Karni A 2005. Lower brain-derived neurotrophic factor in serum of relapsing remitting MS: Reversal by glatiramer acetate. $J$ Neuroimmunol 167: 215-218.

Basile E, Gibbs E, Aziz T, Oger J. 2006. During 3 years treatment of primary progressive multiple sclerosis with glatiramer acetate, specific antibodies switch from IgG1 to IgG4. J Neuroimmunol 177: 161-166.

Begum-Haque S, Sharma A, Christy M, Lentini T, OchoaReparaz J, Fayed IF, Mielcarz D, Haque A, Kasper LH 2010. Increased expression of B cell-associated regulatory cytokines by glatiramer acetate in mice with experimental autoimmune encephalomyelitis. J Neuroimmunol 219: 47-53.

Benner EJ, Mosley RL, Destache CJ, Lewis TB, Jackson-Lewis V, Gorantla S, Nemachek C, Green SR, Przedborski S, Gendelman HE. 2004. Therapeutic immunization protects dopaminergic neurons in a mouse model of Parkinson's disease. Proc Natl Acad Sci 101: 9435-9440.
Ben-Zeev B, Aharoni R, Nissenkorn A, Arnon R. 2011. Glatiramer acetate (GA, Copolymer-1) an hypothetical treatment option for Rett syndrome. Med Hypotheses 76: 190193.

Biegler BW, Yan SX, Ortega SB, Tennakoon DK, Racke MK, Karandikar NJ. 2006. Glatiramer acetate (GA) therapy induces a focused, oligoclonal $\mathrm{CD} 8^{+} \mathrm{T}$-cell repertoire in multiple sclerosis. J Neuroimmunol 180: 159-171.

Blanco Y, Moral EA, Costa M, Gomez-Choco M, TorresPeraza JF, Alonso-Magdalena L, Alberch J, Jaraquemada D, Arbizu T, Graus F, et al. 2006. Effect of glatiramer acetate (Copaxone) on the immunophenotypic and cytokine profile and BDNF production in multiple sclerosis: A longitudinal study. Neurosci Lett 406: 270-275.

Bornstein MB, Miller AI, Teitelbaum D, Arnon R, Sela M. 1982. Multiple sclerosis: Trial of a synthetic polypeptide. Ann Neurol 11: 317-319.

Bornstein MB, Miller A, Slagle S, Weitzman M, Crystal H, Drexler E, Keilson M, Merriam A, Wassertheil-Smoller S, Spada V, et al. 1987. A pilot trial of Cop 1 in exacerbatingremitting multiple sclerosis. N Engl J Med 317: 408-414.

Brenner T, Arnon R, Sela M, Abramsky O, Meiner Z, RivenKreitman R, Tarcik N, Teitelbaum D. 2001. Humoral and cellular immune responses to copolymer 1 in multiple sclerosis patients treated with Copaxone. J Neuroimmunol 115: 152-160.

Brod SA, Lindsey JW, Wolinsky JS. 2000. Combination therapy with glatiramer acetate (copolymer-1) and a type interferon (IFN- $\alpha$ ) does not improve experimental autoimmune encephalomyelitis. Ann Neurol 47: 127-131.

Bruck W, Gold R, Lund BT, Oreja-Guevara C, Prat A, Spencer CM, Steinman L, Tintore M, Vollmer TL, Weber MS, et al. 2013. Therapeutic decisions in multiple sclerosis: Moving beyond efficacy. JAMA Neurol 70: 1315-1324.

Burger D, Molnarfi N, Weber MS, Brandt KJ, Benkhoucha M, Gruaz L, Chofflon M, Zamvil SS, Lalive PH. 2009. Glatiramer acetate increases IL-1 receptor antagonist but decreases T cell-induced IL- $1 \beta$ in human monocytes and multiple sclerosis. Proc Natl Acad Sci 106: 43554359.

Butovsky O, Koronyo-Hamaoui M, Kunis G, Ophir E, Landa G, Cohen H, Schwartz M. 2006. Glatiramer acetate fights against Alzheimer's disease by inducing dendritic-like microglia expressing insulin-like growth factor 1 . Proc Natl Acad Sci 103: 11784-11789.

Cadavid D, Wolansky LJ, Skurnick J, Lincoln J, Cheriyan J, Szczepanowski K, Kamin SS, Pachner AR, Halper J, Cook SD. 2009. Efficacy of treatment of MS with IFN $\beta-1 b$ or glatiramer acetate by monthly brain MRI in the BECOME study. Neurology 72: 1976-1983.

Carpintero R, Brandt KJ, Gruaz L, Molnarfi N, Lalive PH, Burger D. 2010. Glatiramer acetate triggers PI3Kס/Akt and MEK/ERK pathways to induce IL-1 receptor antagonist in human monocytes. Proc Natl Acad Sci 107: 17692-17697.

Carter NJ, Keating GM. 2010. Glatiramer acetate: A review of its use in relapsing-remitting multiple sclerosis and in delaying the onset of clinically definite multiple sclerosis. Drugs 70: 1545-1577.

Chabot S, Yong FP, Le DM, Metz LM, Myles T, Yong VW. 2002. Cytokine production in T lymphocyte-microglia interaction is attenuated by glatiramer acetate: A mecha- 
nism for therapeutic efficacy in multiple sclerosis. Mult Scler 8: 299-306.

Chen M, Valenzuela RM, Dhib-Jalbut S. 2003. Glatiramer acetate-reactive $\mathrm{T}$ cells produce brain-derived neurotrophic factor. J Neurol Sci 215: 37-44.

Cohen JA, Rovaris M, Goodman AD, Ladkani D, Wynn D, Filippi M, Study G. 2007. Randomized, double-blind, dose-comparison study of glatiramer acetate in relapsing-remitting MS. Neurology 68: 939-944.

Comi G, Filippi M, Wolinsky JS. 2001. European/Canadian multicenter, double-blind, randomized, placebo-controlled study of the effects of glatiramer acetate on magnetic resonance imaging-Measured disease activity and burden in patients with relapsing multiple sclerosis. European/Canadian Glatiramer Acetate Study Group. Ann Neurol 49: 290-297.

Comi G, Martinelli V, Rodegher M, Moiola L, Bajenaru O, Carra A, Elovaara I, Fazekas F, Hartung HP, Hillert J, et al. 2009. Effect of glatiramer acetate on conversion to clinically definite multiple sclerosis in patients with clinically isolated syndrome (PreCISe study): A randomised, double-blind, placebo-controlled trial. Lancet 374: 1503 1511.

Comi G, Cohen JA, Arnold DL, Wynn D, Filippi M, Group FS. 2011. Phase III dose-comparison study of glatiramer acetate for multiple sclerosis. Ann Neurol 69: 75-82.

Dhib-Jalbut S. 2002. Mechanisms of action of interferons and glatiramer acetate in multiple sclerosis. Neurology 58: S3-S9.

Duda PW, Schmied MC, Cook SL, Krieger JI, Hafler DA. 2000. Glatiramer acetate (Copaxone) induces degenerate, Th2-polarized immune responses in patients with multiple sclerosis. J Clin Invest 105: 967-976.

Farina C, Then Bergh F, Albrecht H, Meinl E, Yassouridis A Neuhaus O, Hohlfeld R. 2001. Treatment of multiple sclerosis with Copaxone (COP): Elispot assay detects COP-induced interleukin- 4 and interferon- $\gamma$ response in blood cells. Brain 124: 705-719.

Farina C, Vargas V, Heydari N, Kumpfel T, Meinl E, Hohlfeld R. 2002. Treatment with glatiramer acetate induces specific IgG4 antibodies in multiple sclerosis patients. $J$ Neuroimmunol 123: 188-192.

Filippi M, Rovaris M, Rocca MA, Sormani MP, Wolinsky JS Comi G, European/Canadian Glatiramer Acetate Study G. 2001. Glatiramer acetate reduces the proportion of new MS lesions evolving into "black holes." Neurology 57: 731-733.

Fitzgerald DC, O’Brien K, Young A, Fonseca-Kelly Z, Rostami A, Gran B. 2014. Interferon regulatory factor (IRF) 3 is critical for the development of experimental autoimmune encephalomyelitis. J Neuroinflammation 11: 130.

Ford CC, Johnson KP, Lisak RP, Panitch HS, Shifronis G, Wolinsky JS; Copaxone Study Group. 2006. A prospective open-label study of glatiramer acetate: Over a decade of continuous use in multiple sclerosis patients. Mult Scler 12: 309-320.

Ford C, Goodman AD, Johnson K, Kachuck N, Lindsey JW, Lisak R, Luzzio C, Myers L, Panitch H, Preiningerova J, et al. 2010. Continuous long-term immunomodulatory therapy in relapsing multiple sclerosis: Results from the 15-year analysis of the US prospective open-label study of glatiramer acetate. Mult Scler 16: 342-350.
Fox RJ, Miller DH, Phillips JT, Hutchinson M, Havrdova E, Kita M, Yang M, Raghupathi K, Novas M, Sweetser MT, et al. 2012. Placebo-controlled phase 3 study of oral BG-12 or glatiramer in multiple sclerosis. $N$ Engl J Med 367: 1087-1097.

Frenkel D, Maron R, Burt DS, Weiner HL. 2005. Nasal vaccination with a proteosome-based adjuvant and glatiramer acetate clears $\beta$-amyloid in a mouse model of Alzheimer disease. J Clin Invest 115: 2423-2433.

Fridkis-Hareli M, Strominger JL. 1998. Promiscuous binding of synthetic copolymer 1 to purified HLA-DR molecules. J Immunol 160: 4386-4397.

Fridkis-Hareli M, Teitelbaum D, Gurevich E, Pecht I, Brautbar C, Kwon OJ, Brenner T, Arnon R, Sela M. 1994. Direct binding of myelin basic protein and synthetic copolymer 1 to class II major histocompatibility complex molecules on living antigen-presenting cells-Specificity and promiscuity. Proc Natl Acad Sci 91: 4872-4876.

Fridkis-Hareli M, Teitelbaum D, Pecht I, Arnon R, Sela M. 1997. Binding of copolymer 1 and myelin basic protein leads to clustering of class II MHC molecules on antigenpresenting cells. Int Immunol 9: 925-934.

Gilgun-Sherki Y, Panet H, Holdengreber V, Mosberg-Galili R, Offen D. 2003. Axonal damage is reduced following glatiramer acetate treatment in C57/bl mice with chronicinduced experimental autoimmune encephalomyelitis. Neurosci Res 47: 201-207.

Guo B, Chang EY, Cheng G. 2008. The type I IFN induction pathway constrains Th17-mediated autoimmune inflammation in mice. J Clin Invest 118: 1680-1690.

Gur C, Karussis D, Golden E, Doron S, Ilan Y, Safadi R. 2006. Amelioration of experimental colitis by Copaxone is associated with class-II-restricted CD4 immune blocking. Clin Immunol 118: 307-316.

Haas J, Korporal M, Balint B, Fritzsching B, Schwarz A, Wildemann B. 2009. Glatiramer acetate improves regulatory T-cell function by expansion of naïve $\mathrm{CD} 4^{+} \mathrm{CD} 25^{+}$ FOXP $3^{+} \mathrm{CD} 31^{+} \mathrm{T}$-cells in patients with multiple sclerosis. J Neuroimmunol 216: 113-117.

Hestvik AL, Skorstad G, Price DA, Vartdal F, Holmoy T. 2008. Multiple sclerosis: Glatiramer acetate induces anti-inflammatory $\mathrm{T}$ cells in the cerebrospinal fluid. Mult Scler 14: 749-758.

Hong J, Li N, Zhang X, Zheng B, Zhang JZ. 2005. Induction of $\mathrm{CD} 4^{+} \mathrm{CD} 25^{+}$regulatory T cells by copolymer-I through activation of transcription factor Foxp3. Proc Natl Acad Sci 102: 6449-6454.

Hussien Y, Sanna A, Soderstrom M, Link H, Huang YM. 2001. Glatiramer acetate and IFN- $\beta$ act on dendritic cells in multiple sclerosis. J Neuroimmunol 121: 102-110.

Jee Y, Liu R, Bai XF, Campagnolo DI, Shi FD, Vollmer TL. 2006. Do Th2 cells mediate the effects of glatiramer acetate in experimental autoimmune encephalomyelitis? Int Immunol 18: 537-544.

Jee Y, Piao WH, Liu R, Bai XF, Rhodes S, Rodebaugh R, Campagnolo DI, Shi FD, Vollmer TL. 2007. CD $4^{+} \mathrm{CD} 25^{+}$ regulatory $\mathrm{T}$ cells contribute to the therapeutic effects of glatiramer acetate in experimental autoimmune encephalomyelitis. Clin Immunol 125: 34-42.

Johnson KP, Brooks BR, Cohen JA, Ford CC, Goldstein J, Lisak RP, Myers LW, Panitch HS, Rose JW, Schiffer RB, et al. 1995. Copolymer 1 reduces relapse rate and improves 
disability in relapsing-remitting multiple sclerosis: Results of a phase III multicenter, double-blind placebocontrolled trial. Neurology 45: 1268-1276.

Johnson KP, Brooks BR, Cohen JA, Ford CC, Goldstein J, Lisak RP, Myers LW, Panitch HS, Rose JW, Schiffer RB, et al. 1998. Extended use of glatiramer acetate (Copaxone) is well tolerated and maintains its clinical effect on multiple sclerosis relapse rate and degree of disability. Neurology 50: 701-708.

Johnson KP, Brooks BR, Ford CC, Goodman AD, Lisak RP, Myers LW, Pruitt AA, Rizzo MA, Rose JW, Weiner LP, et al. 2003. Glatiramer acetate (Copaxone): Comparison of continuous versus delayed therapy in a 6-year organized multiple sclerosis trial. Mult Scler 9: 585-591.

Johnson KP, Ford CC, Lisak RP, Wolinsky JS. 2005. Neurologic consequence of delaying glatiramer acetate therapy for multiple sclerosis: 8-year data. Acta Neurol Scand 111: $42-47$.

Jung S, Siglienti I, Grauer O, Magnus T, Scarlato G, Toyka K. 2004. Induction of IL-10 in rat peritoneal macrophages and dendritic cells by glatiramer acetate. J Neuroimmunol 148: 63-73.

Kala M, Rhodes SN, Piao WH, Shi FD, Campagnolo DI, Vollmer TL. 2010. B cells from glatiramer acetate-treated mice suppress experimental autoimmune encephalomyelitis. Exp Neurol 221: 136-145.

Kantengwa S, Weber MS, Juillard C, Benkhoucha M, Fellay B, Zamvil SS, Gougeon ML, Chofflon M, Lalive PH. 2007. Inhibition of naive Th $1 \mathrm{CD} 4^{+} \mathrm{T}$ cells by glatiramer acetate in multiple sclerosis. J Neuroimmunol 185: 123-129.

Karandikar NJ, Crawford MP, Yan X, Ratts RB, Brenchley JM, Ambrozak DR, Lovett-Racke AE, Frohman EM, Stastny P, Douek DC, et al. 2002. Glatiramer acetate (Copaxone) therapy induces $\mathrm{CD}^{+} \mathrm{T}$ cell responses in patients with multiple sclerosis. J Clin Invest 109: 641-649.

Karussis D, Teitelbaum D, Sicsic C, Brenner T; AC001 Multi-Center Israeli Study Group. 2010. Long-term treatment of multiple sclerosis with glatiramer acetate: Natural history of the subtypes of anti-glatiramer acetate antibodies and their correlation with clinical efficacy. J Neuroimmunol 220: 125-130.

Khan O, Shen Y, Bao F, Caon C, Tselis A, Latif Z, Zak I. 2008 Long-term study of brain $1 \mathrm{H}$-MRS study in multiple sclerosis: Effect of glatiramer acetate therapy on axonal metabolic function and feasibility of long-term H-MRS monitoring in multiple sclerosis. J Neuroimaging 18: 314-319.

Khan O, Rieckmann P, Boyko A, Selmaj K, Zivadinov R, Group GS. 2013. Three times weekly glatiramer acetate in relapsing-remitting multiple sclerosis. Ann Neurol 73: 705-713.

Kieseier BC, Stuve O. 2011. A critical appraisal of treatment decisions in multiple sclerosis-Old versus new. Nat Rev Neurol 7: 255-262.

Kim HJ, Ifergan I, Antel JP, Seguin R, Duddy M, Lapierre Y, Jalili F, Bar-Or A. 2004. Type 2 monocyte and microglia differentiation mediated by glatiramer acetate therapy in patients with multiple sclerosis. J Immunol 172: 71447153.

Kipnis J, Yoles E, Porat Z, Cohen A, Mor F, Sela M, Cohen IR Schwartz M. 2000. T cell immunity to copolymer 1 confers neuroprotection on the damaged optic nerve: Possi- ble therapy for optic neuropathies. Proc Natl Acad Sci 97: 7446-7451.

Lalive PH, Neuhaus O, Benkhoucha M, Burger D, Hohlfeld R, Zamvil SS, Weber MS. 2011. Glatiramer acetate in the treatment of multiple sclerosis: Emerging concepts regarding its mechanism of action. CNS Drugs 25: 401-414.

Laurie C, Reynolds A, Coskun O, Bowman E, Gendelman HE, Mosley RL. 2007. CD4 ${ }^{+}$T cells from copolymer-1 immunized mice protect dopaminergic neurons in the 1-methyl-4-phenyl-1,2,3,6-tetrahydropyridine model of Parkinson's disease. J Neuroimmunol 183: 60-68.

Linker RA, Lee DH, Demir S, Wiese S, Kruse N, Siglienti I, Gerhardt E, Neumann H, Sendtner M, Luhder F, et al. 2010. Functional role of brain-derived neurotrophic factor in neuroprotective autoimmunity: Therapeutic implications in a model of multiple sclerosis. Brain 133: 2248 2263.

Lublin FD, Cofield SS, Cutter GR, Conwit R, Narayana PA, Nelson F, Salter AR, Gustafson T, Wolinsky JS; CombiRx Investigators. 2013. Randomized study combining interferon and glatiramer acetate in multiple sclerosis. Ann Neurol 73: 327-340.

Marta M, Giovannoni G. 2012. Disease modifying drugs in multiple sclerosis: Mechanisms of action and new drugs in the horizon. CNS Neurol Disorders Drug Targets 11: 610-623.

Metz LM, Li D, Traboulsee A, Myles ML, Duquette P, Godin J, Constantin M, Yong VW; GA/Minocycline Study Investigators. 2009. Glatiramer acetate in combination with minocycline in patients with relapsing-Remitting multiple sclerosis: Results of a Canadian, multicenter, doubleblind, placebo-controlled trial. Mult Scler 15: 1183-1194.

Mikol DD, Barkhof F, Chang P, Coyle PK, Jeffery DR, Schwid SR, Stubinski B, Uitdehaag B; REGARD Study Group. 2008. Comparison of subcutaneous interferon $\beta$-1a with glatiramer acetate in patients with relapsing multiple sclerosis (the REbif vs Glatiramer Acetate in Relapsing MS Disease [REGARD] study): A multicentre, randomised, parallel, open-label trial. Lancet Neurol 7: 903-914.

Miller A, Shapiro S, Gershtein R, Kinarty A, Rawashdeh H, Honigman S, Lahat N. 1998. Treatment of multiple sclerosis with copolymer-1 (Copaxone): Implicating mechanisms of Th1 to Th2/Th3 immune-deviation. J Neuroimmunol 92: 113-121.

Miller A, Spada V, Beerkircher D, Kreitman RR. 2008. Longterm (up to 22 years), open-label, compassionate-use study of glatiramer acetate in relapsing-remitting multiple sclerosis. Mult Scler 14: 494-499.

Mindur JE, Valenzuela RM, Yadav SK, Boppana S, DhibJalbut S, Ito K. 2016. IL-27: A potential biomarker for responders to glatiramer acetate therapy. JNeuroimmunol 304: $21-28$.

Molnarfi N, Prod'homme T, Schulze-Topphoff U, Spencer CM, Weber MS, Patarroyo JC, Lalive PH, Zamvil SS. 2015. Glatiramer acetate treatment negatively regulates type I interferon signaling. Neurol Neuroimmunol Neuroinflamm 2: e179.

Neesse A, Michl P, Kunsch S, Gress TM, Steinkamp M. 2009. Glatiramer acetate: A novel therapeutic approach in Crohn's disease? Inflamm Bowel Dis 15: 156-157. 
Neuhaus O, Farina C, Yassouridis A, Wiendl H, Then Bergh F, Dose T, Wekerle H, Hohlfeld R. 2000. Multiple sclerosis: Comparison of copolymer-1- reactive $\mathrm{T}$ cell lines from treated and untreated subjects reveals cytokine shift from Thelper 1 to T helper 2 cells. Proc Natl Acad Sci 97: 74527457.

O'Connor P, Filippi M, Arnason B, Comi G, Cook S, Goodin D, Hartung HP, Jeffery D, Kappos L, Boateng F, et al. 2009. 250 microg or 500 microg interferon $\beta$ - 1 b versus $20 \mathrm{mg}$ glatiramer acetate in relapsing-remitting multiple sclerosis: A prospective, randomised, multicentre study. Lancet Neurol 8: 889-897.

Ozug J, Wudyka S, Gunay NS, Beccati D, Lansing J, Wang J, Capila I, Shriver Z, Kaundinya GV. 2012. Structural elucidation of the tetrasaccharide pool in enoxaparin sodium. Analytical Bioanalytical Chem 403: 2733-2744.

Prinz M, Schmidt H, Mildner A, Knobeloch KP, Hanisch UK, Raasch J, Merkler D, Detje C, Gutcher I, Mages J, et al. 2008. Distinct and nonredundant in vivo functions of IFNAR on myeloid cells limit autoimmunity in the central nervous system. Immunity 28: 675-686.

Prod'homme T, Zamvil SS. 2008. Bench to bedside: Tempering antigen-presenting cells in multiple sclerosis. Nat Med 14: 614-615.

Pul R, Moharregh-Khiabani D, Skuljec J, Skripuletz T, Garde N, Voss EV, Stangel M. 2011. Glatiramer acetate modulates TNF- $\alpha$ and IL-10 secretion in microglia and promotes their phagocytic activity. J Neuroimmune Pharmacol 6: 381-388.

Pul R, Morbiducci F, Skuljec J, Skripuletz T, Singh V, Diederichs U, Garde N, Voss EV, Trebst C, Stangel M. 2012. Glatiramer acetate increases phagocytic activity of human monocytes in vitro and in multiple sclerosis patients. PloS ONE 7: e51867.

Rovaris M, Comi G, Rocca MA, Valsasina P, Ladkani D, Pieri E, Weiss S, Shifroni G, Wolinsky JS, Filippi M, et al. 2007. Long-term follow-up of patients treated with glatiramer acetate: A multicentre, multinational extension of the European/Canadian double-blind, placebo-controlled, MRI-monitored trial. Mult Scler 13: 502-508.

Sanna A, Fois ML, Arru G, Huang YM, Link H, Pugliatti M, Rosati G, Sotgiu S. 2006. Glatiramer acetate reduces lymphocyte proliferation and enhances IL-5 and IL-13 production through modulation of monocyte-derived dendritic cells in multiple sclerosis. Clin Exp Immunol 143: 357-362.

Sarchielli P, Zaffaroni M, Floridi A, Greco L, Candeliere A, Mattioni A, Tenaglia S, Di Filippo M, Calabresi P. 2007. Production of brain-derived neurotrophic factor by mononuclear cells of patients with multiple sclerosis treated with glatiramer acetate, interferon- $\beta 1 \mathrm{a}$, and high doses of immunoglobulins. Mult Scler 13: 313-331.

Sela M, Teitelbaum D. 2001. Glatiramer acetate in the treatment of multiple sclerosis. Exp Opin Pharmacother 2: 1149-1165.

Sellebjerg F, Hedegaard CJ, Krakauer M, Hesse D, Lund H, Nielsen CH, Sondergaard HB, Sorensen PS. 2012. Glatiramer acetate antibodies, gene expression and disease activity in multiple sclerosis. Mult Scler 18: 305-313.

Simone IL, Ceccarelli A, Tortorella C, Bellacosa A, Pellegrini F, Plasmati I, De Caro MF, Lopez M, Girolamo F, Livrea P. 2006. Influence of interferon $\beta$ treatment on quality of life in multiple sclerosis patients. Health Qual Life Outcomes 4: 96.

Skihar V, Silva C, Chojnacki A, Doring A, Stallcup WB, Weiss S, Yong VW. 2009. Promoting oligodendrogenesis and myelin repair using the multiple sclerosis medication glatiramer acetate. Proc Natl Acad Sci 106: 17992-17997.

Soos JM, Stuve O, Youssef S, Bravo M, Johnson HM, Weiner HL, Zamvil SS. 2002. Cutting edge: Oral type I IFN-tau promotes a Th2 bias and enhances suppression of autoimmune encephalomyelitis by oral glatiramer acetate. $J$ Immunol 169: 2231-2235.

Sormani MP, Rovaris M, Valsasina P, Wolinsky JS, Comi G, Filippi M. 2004. Measurement error of two different techniques for brain atrophy assessment in multiple sclerosis. Neurology 62: 1432-1434.

Stapulionis R, Oliveira CL, Gjelstrup MC, Pedersen JS, Hokland ME, Hoffmann SV, Poulsen K, Jacobsen C, VorupJensen T. 2008. Structural insight into the function of myelin basic protein as a ligand for integrin $\alpha \mathrm{M} \beta 2$. $J$ Immunol 180: 3946-3956.

Stasiolek M, Bayas A, Kruse N, Wieczarkowiecz A, Toyka KV, Gold R, Selmaj K. 2006. Impaired maturation and altered regulatory function of plasmacytoid dendritic cells in multiple sclerosis. Brain 129: 1293-1305.

Steinman L, Zamvil SS. 2016. Beginning of the end of twostage theory purporting that inflammation then degeneration explains pathogenesis of progressive multiple sclerosis. Curr Opin Neurol 29: 340-344.

Stuve O, Youssef S, Weber MS, Nessler S, von Budingen HC, Hemmer B, Prod'homme T, Sobel RA, Steinman L, Zamvil SS. 2006. Immunomodulatory synergy by combination of atorvastatin and glatiramer acetate in treatment of CNS autoimmunity. J Clin Invest 116: 1037-1044.

Teitelbaum D, Meshorer A, Hirshfeld T, Arnon R, Sela M. 1971. Suppression of experimental allergic encephalomyelitis by a synthetic polypeptide. Eur J Immunol 1: 242248.

Teitelbaum D, Webb C, Meshorer A, Arnon R, Sela M. 1973. Suppression by several synthetic polypeptides of experimental allergic encephalomyelitis induced in guinea pigs and rabbits with bovine and human basic encephalitogen. Eur J Immunol 3: 273-279.

Teitelbaum D, Webb C, Bree M, Meshorer A, Arnon R, Sela M. 1974. Suppression of experimental allergic encephalomyelitis in Rhesus monkeys by a synthetic basic copolymer. Clin Immunol Immunopathol 3: 256-262.

Teitelbaum D, Milo R, Arnon R, Sela M. 1992. Synthetic copolymer 1 inhibits human T-cell lines specific for myelin basic protein. Proc Natl Acad Sci 89: 137-141.

Teitelbaum D, Fridkis-Hareli M, Arnon R, Sela M. 1996. Copolymer 1 inhibits chronic relapsing experimental allergic encephalomyelitis induced by proteolipid protein (PLP) peptides in mice and interferes with PLP-specific T cell responses. J Neuroimmunol 64: 209-217.

Teitelbaum D, Arnon R, Sela M. 1999. Immunomodulation of experimental autoimmune encephalomyelitis by oral administration of copolymer 1. Proc Natl Acad Sci 96: 3842-3847.

Teitelbaum D, Brenner T, Abramsky O, Aharoni R, Sela M, Arnon R. 2003. Antibodies to glatiramer acetate do not interfere with its biological functions and therapeutic efficacy. Mult Scler 9: 592-599. 
Tennakoon DK, Mehta RS, Ortega SB, Bhoj V, Racke MK Karandikar NJ. 2006. Therapeutic induction of regulatory, cytotoxic $\mathrm{CD}^{+} \mathrm{T}$ cells in multiple sclerosis. JImmunol 176: 7119-7129.

Toker A, Slaney CY, Backstrom BT, Harper JL. 2011. Glatir-

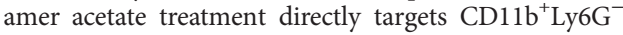
monocytes and enhances the suppression of autoreactive $\mathrm{T}$ cells in experimental autoimmune encephalomyelitis. Scand J Immunol 74: 235-243.

Tyler AF, Mendoza JP, Firan M, Karandikar NJ. 2013. CD8 ${ }^{+}$ $\mathrm{T}$ cells are required for glatiramer acetate therapy in autoimmune demyelinating disease. PloS ONE 8: e66772.

Ure DR, Rodriguez M. 2002. Polyreactive antibodies to glatiramer acetate promote myelin repair in murine model of demyelinating disease. FASEB J 16: 1260-1262.

Varkony H, Weinstein V, Klinger E, Sterling J, Cooperman H, Komlosh T, Ladkani D, Schwartz R. 2009. The glatiramoid class of immunomodulator drugs. Exp Opin Pharmacother 10: 657-668

Venkataraman G, Shriver Z, Raman R, Sasisekharan R. 1999. Sequencing complex polysaccharides. Science 286: 537542.

Venken K, Hellings N, Broekmans T, Hensen K, Rummens $\mathrm{JL}$, Stinissen P. 2008. Natural naive $\mathrm{CD} 4^{+} \mathrm{CD} 25^{+}$ $\mathrm{CD} 127^{\text {low }}$ regulatory T cell (Treg) development and function are disturbed in multiple sclerosis patients: Recovery of memory Treg homeostasis during disease progression. J Immunol 180: 6411-6420.

Vieira PL, Heystek HC, Wormmeester J, Wierenga EA, Kapsenberg ML. 2003. Glatiramer acetate (copolymer-1, copaxone) promotes Th2 cell development and increased IL-10 production through modulation of dendritic cells. J Immunol 170: 4483-4488.
Weber MS, Starck M, Wagenpfeil S, Meinl E, Hohlfeld R, Farina C. 2004. Multiple sclerosis: Glatiramer acetate inhibits monocyte reactivity in vitro and in vivo. Brain 127: 1370-1378.

Weber MS, Prod'homme T, Youssef S, Dunn SE, Rundle CD Lee L, Patarroyo JC, Stuve O, Sobel RA, Steinman L, et al. 2007. Type II monocytes modulate $\mathrm{T}$ cell-mediated central nervous system autoimmune disease. Nat Med 13 935-943.

Wolinsky JS, Comi G, Filippi M, Ladkani D, Kadosh S, Shifroni G; European/Canadian Glatiramer Acetate Study Group. 2002. Copaxone's effect on MRI-monitored disease in relapsing MS is reproducible and sustained. $\mathrm{Neu}$ rology 59: 1284-1286.

Wolinsky JS, Narayana PA, O'Connor P, Coyle PK, Ford C, Johnson K, Miller A, Pardo L, Kadosh S, Ladkani D, et al. 2007. Glatiramer acetate in primary progressive multiple sclerosis: Results of a multinational, multicenter, doubleblind, placebo-controlled trial. Ann Neurol 61: 14-24.

Zamvil SS, Steinman L. 2011. Combining statins with interferon $\beta$ in multiple sclerosis: Think twice, it might not be all right. Lancet Neurol 10: 672-673.

Zhang M, Chan CC, Vistica B, Hung V, Wiggert B, Gery I. 2000. Copolymer 1 inhibits experimental autoimmune uveoretinitis. J Neuroimmunol 103: 189-194.

Ziemssen T, Neuhaus O, Hohlfeld R. 2001. Risk-benefit assessment of glatiramer acetate in multiple sclerosis. Drug Safety 24: 979-990.

Ziemssen T, Kumpfel T, Klinkert WE, Neuhaus O, Hohlfeld R. 2002. Glatiramer acetate-specific T-helper 1- and 2type cell lines produce BDNF: Implications for multiple sclerosis therapy. Brain-derived neurotrophic factor Brain 125: 2381-2391. 


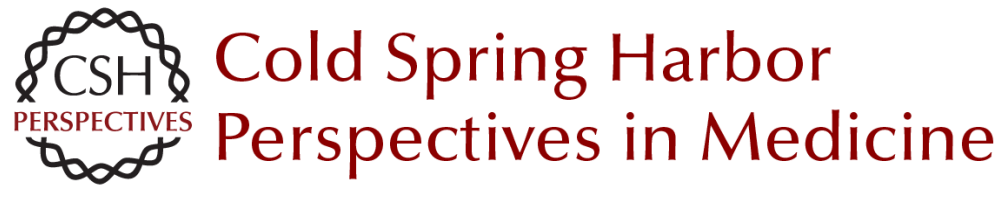

\section{The Evolving Mechanisms of Action of Glatiramer Acetate}

Thomas Prod'homme and Scott S. Zamvil

Cold Spring Harb Perspect Med 2019; doi: 10.1101/cshperspect.a029249 originally published online February 12, 2018

\section{Subject Collection Multiple Sclerosis}

Multiple Sclerosis Pathology Hans Lassmann

Regulatory T Cells: From Discovery to Autoimmunity Alexandra Kitz, Emily Singer and David Hafler

The Multiple Roles of B Cells in Multiple Sclerosis and Their Implications in Multiple Sclerosis Therapies Rui Li and Amit Bar-Or

Autologous Hematopoietic Stem Cell Transplantation in the Treatment of Multiple Sclerosis Carolina A. Rush, Harold L. Atkins and Mark S. Freedman

B-Cell Therapies in Multiple Sclerosis Joseph J. Sabatino, Jr., Scott S. Zamvil and Stephen L. Hauser

Oral Therapies for Multiple Sclerosis Simon Faissner and Ralf Gold

Interferon $\beta$ for Multiple Sclerosis Dejan Jakimovski, Channa Kolb, Murali Ramanathan, et al.

Alemtuzumab as Treatment for Multiple Sclerosis Serafeim Katsavos and Alasdair Coles

\author{
Natalizumab: Perspectives from the Bench to \\ Bedside \\ Afsaneh Shirani and Olaf Stüve \\ Daclizumab Therapy for Multiple Sclerosis \\ Bibiana Bielekova
}

Lifestyle and Environmental Factors in Multiple Sclerosis Lars Alfredsson and Tomas Olsson

Biomarkers in Multiple Sclerosis Anu Paul, Manuel Comabella and Roopali Gandhi

The Evolving Mechanisms of Action of Glatiramer Acetate Thomas Prod'homme and Scott S. Zamvil

Regulation of Astrocyte Functions in Multiple Sclerosis

Michael A. Wheeler and Francisco J. Quintana

Experimental Autoimmune Encephalomyelitis

(EAE) as Animal Models of Multiple Sclerosis (MS) Simon Glatigny and Estelle Bettelli

Neurodegeneration in Progressive Multiple Sclerosis Graham Campbell and Don Mahad

For additional articles in this collection, see http://perspectivesinmedicine.cshlp.org/cgi/collection/ 